\title{
A Evolução do Petismo (2002-2008)
}

\author{
David Samuels \\ Department of Political Science \\ University of Minnesota
}

\begin{abstract}
Resumo: Com base no ESEB 2002 e no LAPOP 2007, o artigo analisa a evolução das bases do apoio de massa ao Partido dos Trabalhadores desde que Lula chegou ao poder em 2002. Historicamente, só o PT tem sido capaz de construir e manter uma ampla base de "identificados" com o partido entre os eleitores brasileiros. Mas, desde 2002, o PT tornou-se mais moderado e muito menos preocupado com os princípios ideológicos e partidários de seus anos iniciais e o artigo investiga o impacto da moderação da liderança do PT sobre os petistas. Os resultados sugerem que houve poucas mudanças nas bases do petismo: uma leve moderação e uma pequena mudança no perfil socioeconômico. Indicam também que o sentimento com relação à corrupção permanece sem importância como determinante do petismo.
\end{abstract}

Palavras-chave: Partido dos Trabalhadores; identificação partidária; ideologia política; pragmatismo.

\begin{abstract}
On the bases of ESEB 2002 and in LAPOP 2007, the article analyzes the evolution of the bases of the support of mass to the PT since Lula took office in 2002. Historically, only the PT has been able to build and maintain a fairly large base of partisan "identifiers" among Brazilian voters. But, since 2002, the PT became more moderate and far less concerned with ideology and with the principles the party laid out in its early years and the article investigates the impact of the moderation of the PT's leadership on the "petistas". The results suggest that it had few changes in the bases of "petismo": a slight moderation and a small change in socioeconomic profile. They also indicate that the sentiment about corruption remains unimportant as a determinant of "petismo".
\end{abstract}

Keywords: Partido dos Trabalhadores; partisan identification; political ideology; pragmatism. 
Este artigo investiga a evolução das bases do apoio de massa ao Partido dos Trabalhadores desde que Lula chegou ao poder em 2002. Em artigo anterior, no qual explorei os dados do ESEB2002, sugeri que o petismo é um fenômeno associado à combinação de três fatores: os esforços intensos de recrutamento, as motivações dos indivíduos para obtenção de informação política e o engajamento dos indivíduos em redes sociais altamente politizadas (SAMUELS, 2006). A combinação das três condições parece necessária, pois, se, por um lado, outros partidos brasileiros desenvolveram atividades de recrutamento e, por outro, muitos brasileiros são motivados para obtenção de informação e/ou engajamento político, apenas o petismo apresenta as três dinâmicas combinadas. Assim, somente o PT tem sido capaz de construir e manter uma ampla base de "identificados" com o partido entre os eleitores brasileiros.

Entretanto, desde a eleição de Lula em 2002, estudiosos e observadores da política brasileira têm sugerido que o PT transformou-se de forma dramática: tornou-se mais moderado, muito mais acomodado à estratégia do "toma lá dá cá" da política brasileira e muito menos preocupado com os princípio ideológicos e partidários de seus anos iniciais (SAMUELS, 2008). Esta conclusão cabe, certamente, à liderança do PT - e esta transformação na cúpula não deveria causar surpresa aos que são familiarizados com a trajetória histórica da maioria dos partidos de esquerda - como mostram as discussões de Marx e Lasalle na Crítica ao Programa de Gotha - e especialmente com a transformação dos partidos de esquerda quando ascendem ao poder - como mostram as discussões de Michels com seu tutor Weber quanto à direção do mesmo partido debatido por Marx e Lasalle cinquenta anos antes.

Neste breve artigo, analiso o impacto da moderação da liderança do PT sobre os apoiadores do partido, os "petistas". Em que medida o perfil do petista médio mudou desde que Lula assumiu a Presidência da República? Vamos considerar três hipóteses: a primeira, a da não moderação dos petistas, apesar de os líderes do partido terem se moderado; a segunda, a da moderação tanto dos líderes quanto dos petistas; e a terceira, de que embora possamos estar bastante certos de que os líderes do partido se moderaram, não podemos afirmar, de fato, o mesmo dos petistas, porque precisaríamos descartar a possibilidade de que o eleitorado brasileiro como um todo teria se moderado. Dadas as tendências globais, devemos considerar seriamente esta terceira possibilidade, tanto quanto as outras duas.

Conhecer a origem da mudança do eleitor é importante para compreender a evolução histórica do sistema político brasileiro. Se pudermos, por exemplo, isolar o timing da mudança na base de apoio do PT, podemos ter alguma compreensão sobre a origem da mudança nos quadros superiores do partidos. Por exemplo, Hunter (2007) sugeriu que o PT foi "empurrado" em direção à moderação por 
forças exógenas e por sua liderança, particularmente Lula e seu círculo mais próximo, na busca pela conquista da Presidência da República desde 1989. Este argumento não implica diretamente que os petistas devam ser menos ou mais moderados, mas sugere sim, indiretamente, uma distância ideológica substantiva e a perda de responsividade entre as bases e a liderança. Se Hunter e outros que enfocam Lula e as maquinações da cúpula estão corretos, então é possível que os apoiadores do partido não tenham se moderado, mas, sim, permanecido, de forma obstinada, motivados mais ideologicamente do que pragmaticamente. Neste cenário, Lula e sua equipe moveram-se para o centro, em parte porque quiseram, e em parte porque as bases partidárias eram incapazes de impedi-los de fazê-lo. Esse não seria um resultado incomum na política partidária, mas se o partido foi empurrado para o centro, tal como Hunter sugere, então talvez as bases petistas permaneçam elas próprias mais ideologicamente comprometidas.

Por outro lado, é possível que os apoiadores do partido compartilhem o desejo de moderação da liderança. Neste cenário, ninguém voluntariamente se empurraria para lugar algum, porque as bases petistas estariam já moderadas na época em que Lula foi eleito Presidente da República. A origem da moderação gradual reside no fato de que muitos da base provaram e gostaram do poder ao nível municipal ou estadual durante a década de 1990 e esta experiência imbuiu muitos petistas do conhecimento de governar e necessariamente impôs um grau de pragmatismo mesmo entre aqueles da ala esquerda do partido. Tenho expressado essa posição em vários trabalhos (SAMUELS, 2004). Esse argumento implica que o petista médio cresceu progressivamente mais moderado no tempo, mesmo antes de Lula chegar à Presidência do país. Lula pode ter querido mover-se para o centro, mas ele sempre foi moderado dentro do partido. Deste modo, Lula não mudou, foram as bases partidárias que mudaram. A questão é quando a maior parte desse processo ocorreu.

Como mencionamos, também precisamos considerar a terceira hipótese. Hunter e eu próprio descartamos a importância da mudança societal - ou seja, que as preferências de todos os eleitores brasileiros evoluem no tempo, empurrando o PT e os outros partidos brasileiros em direção ao centro do espectro político. Os eleitores brasileiros não parecem ter sido encantados pelo estilo nacionalista de Hugo Chavez; além disso, a ideologia, que nunca definiu realmente uma clivagem profunda na política brasileira, continua com um papel mínimo na diferenciação entre partidos na era contemporânea.

Neste artigo, abordo a evolução do eleitorado brasileiro como um todo. Enfoco a questão mais estreita sobre a origem da evolução potencial do apoio de massa petista e deixo a questão sociológica mais ampla para outro momento. Além disso, a questão mais estreita é tão importante quanto relevante à luz dos escândalos que ocorreram no primeiro governo Lula. Dados os contínuos esforços 
do PT em apresentar-se como "diferente" dos demais partidos brasileiros, especialmente em termos de sua devoção aos princípios do governo limpo, os escândalos causaram muita especulação sobre o seu futuro.

Para começar, o Gráfico 1 apresenta o cenário da evolução da preferência partidária desde 1989, desagregado para os três maiores partidos brasileiros, com base em dados do Instituto Datafolha.

\section{Gráfico 1 - Evolução da Preferência Partidária no Brasil,} 1989-2008

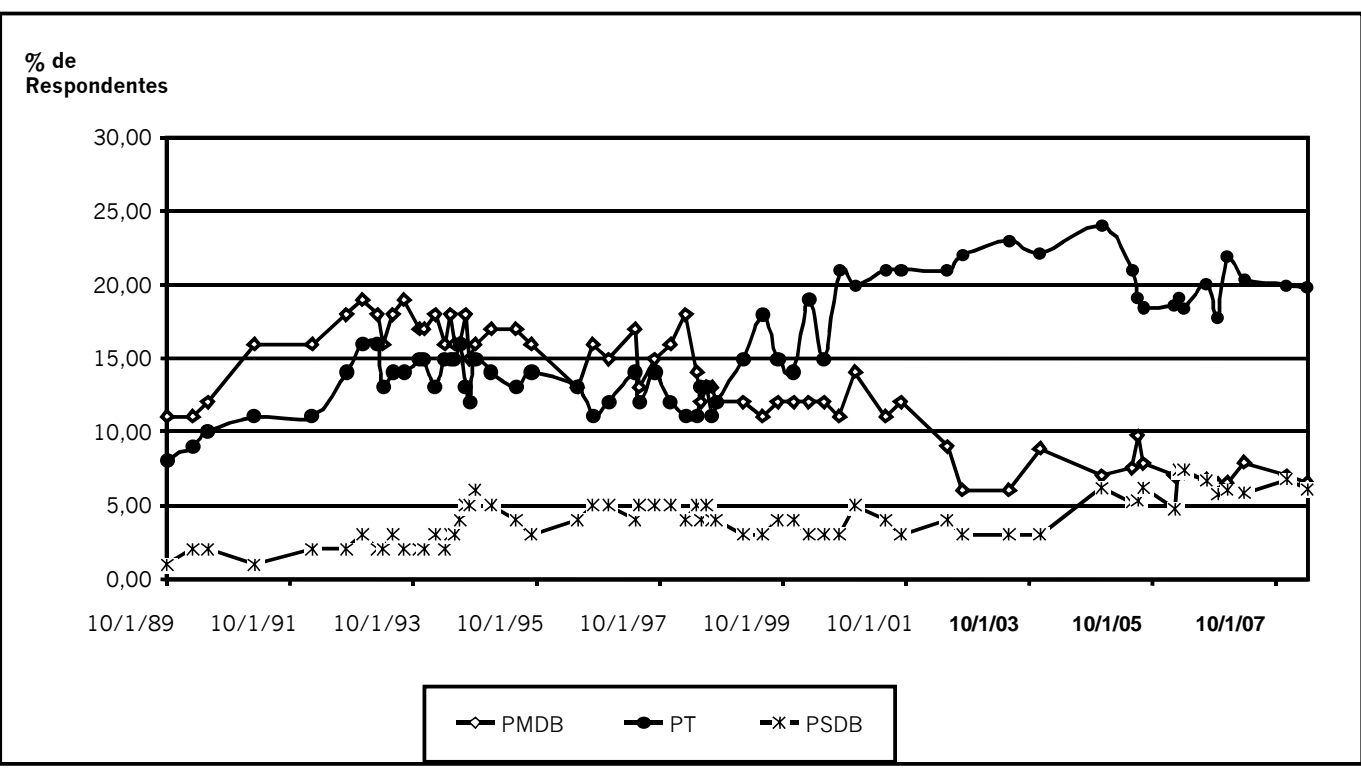

Fonte: Datafolha, 1989; 1991; 1993; 1995; 1997; 1999; 2001; 2003; 2005; 2007.

O Gráfico 1 mostra três conjuntos de informação: primeiro, a perda pelo PMDB, de forma consistente no tempo, de seus apoiadores, com sua preferência caindo entre o eleitorado de $15 \%$ para $7 \%$. Segundo, o PSDB, partido governante de 1995 a 2002, conseguiu atrair apenas entre 6\% e 7\% dos cidadãos brasileiros como seus fortes apoiadores. Terceiro, e o mais importantes para este artigo, a proporção de brasileiros que expressam preferência pelo PT cresceu de forma mais ou menos consistente de por volta de 5\% em 1989 para perto de 20\% em 2004. Entretanto, desde os escândalos de corrupção que colocaram uma nuvem negra sobre o PT e sobre a administração Lula em 2005, o partido perdeu seu momento de crescimento e apenas conseguiu manter um nível de preferência entre por volta de $20 \%$ do eleitorado, ao menos segundo as pesquisas do Datafolha. 
A questão-chave para este artigo é a comparação entre os níveis de petismo em 2002 e 2007-8. De acordo com aquelas pesquisas, a proporção de brasileiros identificados com o PT em junho de 2002 era de $21 \%$ e a proporção em março de 2008 era 20\%. Se usamos esses dados como pontos de referência, então, o PT nem ganhou nem perdeu apoio como conseqüência de qualquer coisa feita pela administração Lula ou pelo PT desde 2002. Entretanto, segundo Veiga (2007), as pesquisas ESEB2002 e ESEB2006 mostram um quadro de declínio na preferência partidária para todos os maiores partidos brasileiros, incluindo o PT. Isso traz um problema para interpretar o que "realmente" está acontecendo. Uma das proposições deste artigo é levantar a questão da validade da comparação entre o ESEB2002, ESEB2006 e LAPOP2007. Pessoalmente, suspeito que a diferença no tamanho das amostras do ESEB2002 e LAPOP2007 pode afetar a comparação, e deveríamos considerar com cuidado quaisquer inferências resultantes dessa análise.

Com esse ponto em mente, vou apenas realizar uma comparação: estou interessado em saber se o perfil do petista médio mudou entre 2002 e 2007. Ao longo dos últimos vinte anos, o PT cresceu de um partido eminentemente paulista para uma máquina nacional e poderia se esperar que seus crescimento e expansão seriam acompanhados pela mudança concomitante do perfil de sua base de apoio de massa. Entretanto, a questão reside na extensão e natureza de tal mudança durante os últimos poucos anos. Se descobrirmos que o perfil do petista médio não mudou nesse tempo, sabemos que a maior mudança no perfil ocorreu antes de 2002.

Veiga (2007) já havia apontado para essa questão, e mencionado que a comparação das porcentagens agregadas dos ESEB2002 e 2006 revelara o declínio dos vínculos partidários do PT e apontava ainda para uma mudança dramática do perfil do petista médio no mesmo período. Especificamente, a autora sugeriu que os identificados com o PT tornaram-se menos escolarizados, mais pobres, mais conservadores politicamente e com menor possibilidade de pertencerem à região sudeste do país. Ela infere, portanto, que parte dos apoiadores petistas de esquerda agora apoiam o PSOL ou não mostram vínculo com o partido, mesmo tendo o PT ganho a adesão de "centristas" que poderiam não ter qualquer identidade partidária prévia.

Infelizmente, as inferências de Veiga são metodologicamente questionáveis, porque não foi feito o controle das mudanças potenciais básicas em quaisquer das variáveis independentes entre as duas pesquisas. A auto-classificação média dos brasileiros na escala esquerda-direita era 5,3 em 2002, mas quase 5,8 em 2006 e, portanto, mais conservadora. Esta mudança poderia ter ocorrido porque apenas os petistas ficaram mais conservadores, enquanto outros brasileiros não teriam mudado nada; ou poderia ser porque os apoiadores do PSDB ou do DEM ficaram 
mais conservadores, precisamente devido à sua oposição a Lula e ao PT, enquanto a identidade esquerda-direita dos apoiadores do PT e do restante dos demais brasileiros teria continuado exatamente a mesma; ou, por fim, teria ocorrido porque todos os brasileiros ficaram mais conservadores ${ }^{1}$.

Precisamos saber se os petistas, comparados ao restante da população brasileira, têm maior possibilidade de se auto-classificarem ou não como esquerdistas nas duas pesquisas. Comparações de tabelas cruzadas entre as duas pesquisas não podem responder à questão, e uma melhor abordagem é a análise estatística multivariada, de forma a confirmar ou não, de forma estatística e significante, se uma determinada variável diferencia os petistas dos outros brasileiros em cada uma das pesquisas.

\section{1 - Bases potenciais do petismo}

Dando seqüência a trabalho anterior sobre esse tema (SAMUELS, 2004), na análise a seguir eu enfoco quatro conjuntos de hipóteses sobre as bases do petismo: 1) identidades de grupo; 2) inserção em redes sociais; 3) contexto demográfico e 4) atributos individuais.

\section{1 - Identidades de grupo}

Esta hipótese sugere que a preferência partidária é um reflexo sociológico do pertencimento dos cidadãos a grupos mais ou menos objetivamente definidos. Incluí algumas variáveis que os estudiosos têm sugerido serem associadas à evolução das atitudes partidárias. No Brasil, entretanto, os estudiosos geralmente esperam que poucas dessas variáveis sejam fortemente associadas à preferência partidária por qualquer partido (p.ex. Mainwaring, Meneguello e Power, 2000). Especificamente, exploro as conexões potenciais entre o petismo e as seguintes variáveis independentes: gênero, idade (em anos), raça (brancos e não-brancos), religião (católica ou não, evangélica ou não) e renda familiar (em Reais para 2002, em salários mínimos para 2007).

\footnotetext{
1 Isso pode também ser função da medida aleatória de erro. Seria verdadeiramente notável que duas pesquisas realizadas com a diferença de quatro anos mostrassem exatamente o mesmo indicador médio de auto-localização esquerda-direita do cidadão.
} 


\section{2 - Inserção em redes sociais}

Para alguns estudiosos, os elementos mais importantes para a preferência partidária não são as identidades de grupos ou individuais, mas a natureza e extensão do envolvimento dos cidadãos na política e redes sociais. Esta hipótese pode ser tomada de duas formas: como um teste da noção de que pessoas "mais envolvidas" têm simplesmente mais possibilidade de terem preferência partidária, ou como um teste indireto da noção de que o recrutamento por ativistas sociais aumenta a preferência partidária (CARMINES and STIMSON, 1989; ROSENSTONE and HANSEN, 1993; DALTON and WATTENBERG, 2000). Ambos são provavelmente verdade, porque embora algumas pessoas possam ter maior propensão a participar da política, é preciso ter alguma forma de recrutamento para a maioria das pessoas se envolverem na política. O PT e os petistas têm uma longa e contínua reputação como altamente "engajados" na esfera pública e na sociedade civil.

Em específico, testamos a hipótese de que a inserção em redes sociais está associada ao petismo explorando duas variáveis tipo índice, uma que mede o grau de participação dos entrevistados em Política Eleitoral e uma segunda que mede o grau de participação em Política Não-Eleitoral.

\section{3 - Contexto demográfico}

As pesquisas sugerem que variáveis demográficas estruturais podem estar associadas a tendências mais fortes ou mais fracas de obtenção de preferência partidária. Tais variáveis podem não ser causas aproximadas do partidarismo, mas servem como "proxies" do contexto social, sugerindo que variáveis não medidas, ou talvez não mensuráveis têm papel causal mais direto. O proxy que utilizo para contexto social é o Índice de Desenvolvimento Humano Municipal (IDHM), o que é um índice composto, basicamente, de três indicadores sobre bem-estar humano: 1) expectativa de vida, que reflete as condições de saúde disponíveis à população; 2) o nível educacional, e 3) renda per capita. 0 índice varia de 0 a 1 , com os valores mais altos indicando uma tendência ao maior ou melhor desenvolvimento humano

Minha expectativa é que os municípios com níveis mais altos de IDHM tenham redes de organização social e política mais densas e, portanto, que seus indivíduos tenham maior probabilidade de serem petistas, dada a hipótese de relação entre capital humano e formação de preferências partidárias.

Cidadãos em municípios com um maior capital humano não apenas têm maior probabilidade de participação, mas também têm, relativamente, mais oportunidades de fazê-lo, o que os leva a tomar decisões sobre se devem envolver. se e como. 


\section{4 - Atributos individuais}

Os estudiosos afirmam numerosas conexões entre os atributos dos indivíduos e a preferência partidária, incluindo idade e educação, e a crença na eficácia da democracia. Cidadãos com atitudes positivas sobre a democracia e que acreditam na eficácia da participação política têm maior probabilidade de desenvolverem vínculos partidários.

De forma semelhante, deveríamos explorar se certas atitudes culturais estão associadas à preferência por partidos. A questão chave é se os brasileiros caracterizados por crenças culturais modernas versus tradicionais seriam propensos a desenvolver identificação partidária por partidos específicos (SOARES, 1961; REIS, 1978).

Os atributos individuais específicos explorados incluem: 1) crença na Eficácia do Voto, 2) extensão do Conhecimento Político (uma variável índice); 3) anos de escolaridade; 4) apoio ao Clientelismo (índice); 5) tolerância à corrupção (índice) e 6) apoio à supressão do protesto politico (variável índice). Em um cenário convencional, espera-se que os petistas acreditem que votar tem importância, que tenham maior conhecimento e escolaridade do que a média e que tenham opiniões negativas sobre o clientelismo, o esquema "rouba mas faz"e a supressão do protesto. Certamente, devo mencionar que minha análise dos dados do ESEB2002 encontrou que os petistas não eram mais bem educados do que a média, embora tivessem maior conhecimento de política. Além disso, em 2002, os petistas não tinham opiniões particularmente fortes contra o clientelismo, embora expressassem um grau de aversão à corrupção.

\section{2 - Dados e Medidas}

Para testar as hipóteses acima, utilizei dados do ESEB2002 e LAPOP2007. A variável dependente é a auto-declaração de identificação partidária. Para revelar as relações subjacentes das bases do partidarismo, utilizei o método estatístico da regressão logística multinomial com erros-padrão robustos. Este procedimento estima o impacto das variaveis explicativas sobre uma variável dependente que pode assumir mais do que um valor categórico. Nesse caso, embora eu apenas mostre os resultados da identificação pelo PT, o modelo estatístico estima o impacto das correlações para seis categorias de identificação partidária: PT, PMDB, PSDB ou PFL, outras identificações e nenhuma identificação partidária, sendo esta última a categoria de referência².

\footnotetext{
2 Isso significa que cada coeficiente de regressão nos diz se uma variável independente particular distingue os partidários de cada partido dos brasileiros que não têm identificação partidária.
} 
Cada uma das seis variáveis-índice são operacionalizadas em cada pesquisa precisamente da mesma forma, ou seja, estamos analisando exatamente a mesma questão. Por razões de espaço, a lista de todas as questões que compõem as variáveis-índice não está exposta. A Tabela 1 compara os resultados para as duas pesquisas:

\section{Tabela 1 - Correlações de Petismo, 2002 e 2007}

\begin{tabular}{|l|c|c|}
\hline \multirow{2}{*}{ Variáveis Independentes } & \multicolumn{2}{|c|}{ Coeficientes (E.P) } \\
\cline { 2 - 3 } & $\mathbf{2 0 0 2}$ & $\mathbf{2 0 0 7}$ \\
\hline Ideologia & $.13(.02)^{* * *}$ & $.01(.04)$ \\
\hline Apoio à democracia & $.07(.09)$ & $.04(.11)$ \\
\hline Eficácia do voto & $.25(.06)^{* * *}$ & $.13(.04)^{* * *}$ \\
\hline Branco &. $.10(.13)$ &. $.31(.19)$ \\
\hline Mulher &. $.07(.13)$ &. $.37(.17)^{*}$ \\
\hline Idade & $.01(.01)$ & $.01(.01)$ \\
\hline IDHM & $2.95(.99)^{* *}$ & $2.92(1.26)^{* *}$ \\
\hline Anos de escolaridade & $.01(.02)$ &. $.04(.02)^{*}$ \\
\hline Renda Familiar & $.01(.01)$ & $.05(.07)$ \\
\hline Evangélico & $.07(.23)$ & $.03(.32)$ \\
\hline Católico & $.15(.19)$ &. $.13(.20)$ \\
\hline Apoio à censura & $.05(.02)^{* *}$ & $.02(.01)^{*}$ \\
\hline Conhecimento político & $.11(.03)^{* * *}$ & $.16(.08)^{+}$ \\
\hline Participação eleitoral & $.18(.03)^{* * *}$ & $.15(.04)^{* * *}$ \\
\hline Não-participação política & $.07(.07)$ & $.04(.06)$ \\
\hline Apoio ao clientelismo & $.02(.01)$ & $.06(.03)^{*}$ \\
\hline Apoio ao "Rouba mas Faz" & $.01(.01)$ &. $.03(.02)$ \\
\hline Constante & $.4 .15(.88)^{* * * *}$ & $.5 .57(1.09)^{* * *}$ \\
\hline & & \\
\hline N & 2491 & 1214 \\
\hline Pseudo-r ${ }^{2}$ & .12 & .10 \\
\hline Log pseudolikelihood & .2311 .38 & .1083 .47 \\
\hline
\end{tabular}

${ }^{* * *} p>.001,{ }^{* *} p>.01,{ }^{*} p>.05,{ }^{+} p>.10$.

Fonte: ESEB, 2002; LAPOP-Brasil, 2007.

A comparação entre 2002 e 2007 revela mudanças intrigantes nas bases do petismo. A distinção mais óbvia é que a ideologia esquerda-direita não prediz mais o petismo. Em 2002, os petistas ainda se auto-localizavam levemente à esquerda em comparação aos brasileiros sem identificação partidária, a categoria base. 
Entretanto, em 2007, a ideologia de esquerda não prediz mais a identificação com o PT, indicando que a moderação petista ao nível de sua elite ao longo da última década teve reflexo sobre sua base de apoio de massa. Matematicamente, este achado implica que a mudança na média global do escore esquerda-direita do eleitorado brasileiro deve-se à mudança entre os petistas, não entre os demais brasileiros - se os apoiadores do DEM, PSDB, PMDB e os demais brasileiros estivessem também se movendo para a direita, então os apoiadores petistas teriam permanecido à esquerda por comparação, a menos que tivessem se movido para a direita duas vezes mais do que os apoiadores dos demais partidos, o que parece improvável.

Esta mudança tem ao menos duas origens potenciais. A primeira é a saída dos petistas mais fortemente esquerdistas das fileiras daqueles que se autodeclaram petistas. Dado que muitos agora associam o partido aos escândalos políticos da admnistração Lula, e dado o óbvio centrismo pragmático, há bases para supor uma saída desse tipo. Existe ainda uma segunda origem potencial para a moderação petista: é possível que o petista médio seja mais moderado hoje do que há vários anos simplesmente porque o partido teve sucesso em atrair novos apoiadores para os quais a ideologia é um aspecto insignificante para o seu petismo. Infelizmente, as duas pesquisas analisadas não perguntaram a questão sobre o tempo de identificação do indivíduo com o PT (ou com qualquer partido), de forma que essa hipótese não tem desdobramento.

Uma terceira origem potencial da mudança da base de massa do petismo é geográfica. Se a base geográfica do apoio petista mudou e os novos apoiadores são de áreas onde a ideologia é relativamente menos importante na política, então, podemos compreender melhor porque a ideologia é agora relativamente sem importância para o petismo. Quando consideramos as bases geográficas do apoio petista no decorrer do tempo, fica claro que o partido tornou-se uma força nacional por conta das duas últimas décadas, mas isso significa que a proporção de petistas oriundos do lugar de origem do partido - São Paulo e os estados do sudeste - tem estado em constante declínio.

O Gráfico 2 mostra as bases regionais do petismo desde 1989 quando as pesquisas nacionais de opinião começaram a aplicar a pergunta sobre preferência partidária ${ }^{3}$.

\footnotetext{
3 As pesquisas incluídas nesta análise são: a pesquisa nacional presidencial de 1989 do Instituto Datafolha ( Banco de dados do CESOP, DAT/BR89.SET-00186), Pesquisa Cultura e Política CEDEC 1993 (Banco de Dados do CESOP, DAT/BR93.MAR-00322), o Estudo Eleitoral Brasileiro 2002. ESEB, e a pesquisa LAPOP 2007.
} 


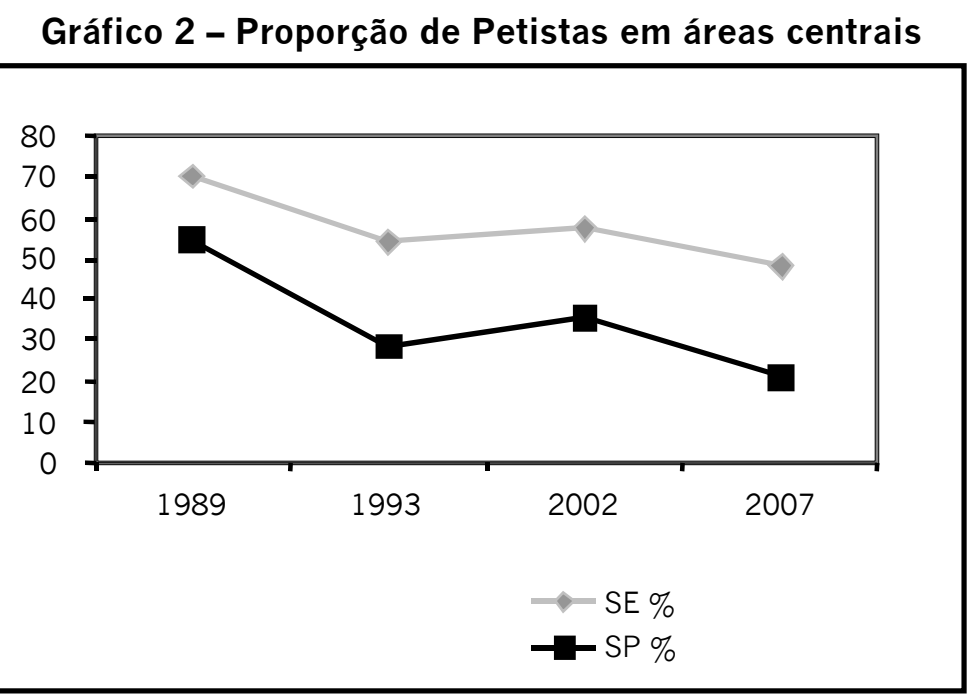

Fonte: Datafolha, 1989; CEDEC/Datafolha; 1993; ESEB, 2002; LAPOP. Brasil, 2007.

De acordo com o Gráfico 2, em 1989, o PT era ainda amplamente um partido paulista e, embora o grupo paulista ainda detenha um enorme poder dentro do partido - especialmente, mas não inteiramente, porque este é o grupo e a base histórica de apoio do Presidente Lula - novas áreas geográficas têm ganho peso dentro do partido.

Em 2007, apenas 20\% de todos os petistas estavam em São Paulo e cerca de $50 \%$ vinham da região sudeste - quase exatamente as proporções estadual e regional da população nacional. Suspeito, mas sem poder confirmar, que os petistas de fora da região de nascimento do partido são menos ideológicos em geral e, portanto, com menor probabilidade de se auto-classificarem como de esquerda, mesmo quando identificados como petistas.

Essa noção coloca as origens da moderação do PT nos seus esforços de recrutamento de novos apoiadores e em sua incapacidade para reter parte dos antigos. Embora esses esforços tenham sido contínuos, foram relativamente mais bem sucedidos fora de São Paulo nos últimos 10 anos ou mais.

Em todo caso, voltando aos resultados da Tabela 1 , qualquer que seja o motivo da moderação ideológica do petista médio, a comparação entre as pesquisas de 2002 e 2007 sugere que as suas principais características em 2007 são que ele ou ela: 1) vive em municípios altamente desenvolvidos; 2) acredita que o voto faz diferença na política; 3) é altamente envolvido na política eleitoral comparado aos indivíduos sem partido da vizinhança; 4) possui um conhecimento politico maior do que o brasileiro médio sem partido. 
Dessa forma, com exceção do resultado sobre ideologia, o retrato do petista médio em 2007 difere pouco daquele obtido em 2002. Observe-se, no entanto, que os resultados de 2007 não são tão robustos comparados aos dados de 2002. Por exemplo, o achado sobre conhecimento político deve ser comparado nas pesquisas segundo os anos de escolaridade: em 2002, os petistas eram mais educados do que os demais brasileiros, mas, em 2007, a análise estatística indica que os petistas têm, em média, menos anos de escolaridade inclusive que os brasileiros sem partido. Esse resultado é surpreendente dada a trajetória histórica do partido e acompanha os achados de Veiga (2007) utilizando os dados do ESEB2006.

Mesmo assim, os resultados sobre as demais variáveis permanecem claramente consistentes ao longo do tempo. Em termos do impacto do contexto sócio-demográfico, o IDHM está positivamente associado ao petismo nos dois anos analisados. O IDHM está positivamente correlacionado à densidade das organizações locais sociais e políticas e, portanto, negativamente correlacionado ao personalismo e clientelismo. E o petismo está associado aos indivíduos que moram em localidades mais altamente desenvolvidas e modernas.

A variável participação eleitoral permanece fortemente associada ao petismo, assim como a variável eficácia do voto. Os petistas continuam altamente engajados na política e acreditam que o envolvimento pode fazer diferença, comparados aos brasileiros sem identificação partidária. Em alguma medida, isso representa um grau de continuidade de longo prazo, dado que o PT emergiu do ativismo associado ao movimento sindical independente, comunidades eclesiais de base e outros movimentos sociais (MENEGUELLO, 1989; KECK, 1992). Entretanto, enquanto o petismo permanece ligado ao ativismo político, note-se que nem em 2002 nem em 2007 existem evidências de que os petistas sejam mais ativos em organizações comunitárias ou outras formas de participação não-eleitoral, comparados aos demais brasileiros. O desenvolvimento de uma identificação partidária é tipicamente associado ao engajamento em redes políticas, ou seja, é "ativado" através de uma associação repetida de longo prazo com a mente dos indivíduos. Assim, a natureza precisa das redes que "ativam" a identificação com o PT merece maior investigação, particularmente dado o fato de que tanto o PT quanto os movimentos sociais no país mudaram consideravelmente desde a redemocratização (HOCHSTETLER, 2004; SAMUELS, 2004), e especialmente dadas as divisões internas do partido e o impacto dos escândalos de corrupção de 2005.

Cabe apontar os resultados consistentes quanto às variáveis apoio ao clientelismo e apoio ao "rouba mas faz". Assim como em 2002, em 2007 os petistas não são favoráveis ao clientelismo, mas eles não dão importância à corrupção. Nas pesquisas, o apoio ao clientelismo foi avaliado perguntando aos entrevistados como eles se sentiam com respeito à troca de votos por pequenos favores ou benefícios pelos políticos. Ao contrário, o apoio ao "rouba mas faz" foi 
avaliado perguntando como os entrevistados se sentiam sobre políticos que "realizavam obras ou medidas" mesmo se algum recurso desaparecesse no processo. O resultado sobre o "rouba mas faz" em 2002 surpreendeu muitos dos que reagiram ao meu trabalho anterior (SAMUELS, 2004), entretanto, o resultado consistente desta variável em 2002 e 2007 deve tornar claro que os petistas fazem uma distinção entre clientelismo e corrupção: eles não são predispostos a trocar seu voto por um pequeno favor, mas não são apaixonados pela transparência ou eficiência no governo.

O resultado desta segunda variável possibilita uma reflexão substantiva sobre o nível de apoio partidário em 2002 e em 2007, qual seja, dado o envolvimento admitido de várias lideranças importantes em escândalos de corrupção, se mais petistas se importassem com o "rouba mas faz", então o partido teria perdido muito mais apoiadores nos últimos anos do que efetivamente ocorreu.

Finalmente, uma das comparações mais interessantes sugere que os petistas inverteram sua opinião sobre a censura governamental: em 2002, os petistas se opunham à censura, mas em 2007 eles são favoráveis. Neste caso, suspeito que seja uma mudança contextual que não reflete a forte transformação na base de apoio de massa do PT. No decorrer da administração Lula, os principais canais de mídia dedicaram-se a cobrir os escândalos de corrupção e colocar os membros do governo sob holofote negativo. Não estou sugerindo que deveriam fazer o oposto, mas é fato que, com o PT no governo, a mídia coloca luz mais forte sobre o partido e o governo federal. Em resposta, Lula e muitos do partido foram levados a difamar repórteres e seus empregadores, e o governo se esforçou para controlar a liberdade de imprensa. Dessa forma, suspeito que os petistas foram contrários à cobertura negativa da imprensa sobre o partido e agora apóiam a censura governamental, mesmo que isso obviamente contradiga tudo o que o PT historicamente sustentou. 


\section{Considerações Finais}

O que podemos apreender da comparação das correlações do petismo nos dados do ESEB2002 e LAPOP2007? Nos dois anos, encontramos que o petista médio vive em centros urbanos relativamente bem desenvolvidos, participa ativamente da política, está relativamente mais informado do que a maioria dos brasileiros, acredita fortemente que seu voto faz diferença para a política e é contrário ao clientelismo, mas importa-se menos com a corrupção.

Em resumo, os resultados sugerem apenas um baixo grau de mudança nas bases do petismo. As principais distinções são que elas tornaram-se levemente mais moderadas e menos escolarizadas, além do que sua origem é menos provável na região sudeste, confirmando parcialmente os achados de Veiga (2007). Entretanto, não há evidências de que os petistas sejam mais pobres do que os demais brasileiros. Suspeito que uma pesquisa adicional mostraria que a maior mudança no perfil dos petistas ocorreu nos anos noventa, antes da primeira gestão presidencial de Lula.

Devo agora comentar a hipótese de que os programas do governo federal, como o Bolsa Família, devem ser considerados para explicar o espalhamento do petismo para fora da região sudeste. Embora não haja evidência direta, duvido muito que este seja o caso, simplesmente porque, enquanto a cobertura desse programa é extremamente ampla, o petismo espalhou-se para fora da região sudeste de forma extremamente lenta, permanecendo não associado à pobreza.

Cabe também apontar que o impacto da variável "educação" deve mostrar de uma vez por todas que não é necessário ser altamente escolarizado para desenvolver vinculações partidárias no Brasil. Alguns estudiosos associam escolaridade e apoio partidário no país (p.ex. MOISÉS, 1992; BALBACHEVSKY, 1992; CARREIRÃO e KINZO, 2002), mas esta conclusão é incorreta. De fato, educação e petismo são negativamente correlacionados quando controlados por outros fatores, tal como os resultados da regressão demonstraram.

A ascensão do PT ao poder federal com a vitória de Lula em 2002 e o impacto dos escândalos de corrupção em seu governo em 2005 levantaram questões pertinentes sobre as bases de apoio do partido. Tanto Lula quanto o PT moveram-se para o centro durante a última década, e a identificação partidária com o partido cresceu no decorrer dos anos noventa e até 2004, sugerindo que o pragmatismo do partido andou de mãos dadas com o crescimento de seu apoio. Ao final dos anos noventa, parece improvável que o PT teria atraído os mais radicais do país para suas fileiras.

De todo modo, no governo, Lula adotou políticas que afastaram os apoiadores petistas, particularmente aqueles da ala esquerda do partido, e os escândalos de corrupção mancharam a reputação petista como baluarte do governo 
limpo. Mesmo assim, o impacto da moderação de Lula e do partido sobre o grau de identificação partidária parece negligenciável, e o impacto da mesma dinâmica sobre a natureza do apoio parece ser pequeno - uma leve moderação e uma pequena mudança no perfil socioeconômico, mas na sua maior parte, sem transformação. Assim como em 2002, a análise estatística sugere que o sentimento com relação à corrupção permanence sem importância como determinante do petismo.

Os esforços contínuos do PT para expandir e consolidar sua estrutura organizacional e recrutar novos membros devem compensar as perdas; os apoiadores recém recrutados devem se importar relativamente pouco se o PT abandonou ou não sua "missão histórica". De todo modo, o desenvolvimento político sob o governo Lula torna o apoio partidário de massa ao PT um aspecto em mudança, e o futuro do partido permanece uma questão em aberto.

Ao longo dos últimos trinta anos, o PT cresceu de um insignificante e localizado ator para uma poderosa força política. Nesse período, o partido desenvolveu recursos substanciais de recrutamento de apoio, atraindo seguidores dentre as classes ativistas do país - aqueles que vivem em áreas desenvolvidas e acreditam que o ativismo político pode fazer diferença. Isso levanta uma questão para o futuro do PT: que tipo de brasileiros continuam a considerá-lo atraente como partido - não apenas uma opção de voto, mas, no limite, de desenvolver uma profunda ligação psicológica que o leve a afirmar "eu sou petista"? Uma outra pesquisa tipo survey e, especialmente, entrevistas em pequenos grupos focais devem conseguir identificar mais profundamente as origens do petismo - descobrir os mecanismos que ligam a motivação individual para participar da política às estratégias partidárias de recrutamento de apoiadores. Dado o recente pragmatismo e a mancha dos escândalos políticos, uma futura pesquisa deve buscar identificar que tipos de pessoas declararam mais recentemente a preferência pelo PT e que tipos decidiram romper sua identificação com o partido. 


\section{Referências Bibliográficas}

CARREIRÃO, Y. S., KINZO, M. D’ALVA. "Os Partidos Políticos e a Decisão de Voto no Brasil." Paper apresentado no Encontro da ABCP, Niterói, 2002.

Datafolha. Vários anos. Surveys da avaliação dos presidentes. Disponível em: $<$ www.folha.uol.com.br/folha/datafolha>.

HOCHSTETLER, K. "Civil Society in Lula's Brazil." Unpublished, Centre for Brazilian Studies, Oxford University, 2004.

HUNTER, W. "The Normalization of an Anomaly: The Workers' Party in Brazil." World Politics, vol.59, n³, p.440-475, 2007.

KECK, M. The Workers' Party and Democratization in Brazil. New Haven: Yale University Press, 1992.

KINZO, M. D’ALVA. “Os Partidos no Eleitorado: Percepções Públicas e Laços Partidários no Brasil." Revista Brasileira de Ciências Sociais, vol.20, n57, p.65-81, 2005.

MAINWARING, S., MENEGUELLO, R., POWER, T. Conservative Parties, Democracy, and Economic Reform in Contemporary Brazil. In: MIDDLEBROOK, K. (ed.). Conservative Parties, the Right, and Democracy in Latin America. Baltimore: The Johns Hopkins University Press, p. 164-222, 2000.

REIS, F. W. (ed.). Os Partidos e o Regime. São Paulo: Símbolo, 1978.

SAMUELS, D. "From Socialism to Social Democracy? Party Organization and the Transformation of the Workers' Party in Brazil." Comparative Political Studies, vol.37, n9, p.999-1024, 2004.

"Sources of Mass Partisanship in Brazil." Latin American Politics and Society, vol.48, n², p.1.27, Summer 2006.

"Brazilian Democracy under Lula and the PT." Forthcoming in: SHIFTER, M., and DOMINGUEZ, J. (eds.). Constructing Democratic Governance in Latin America ( ${ }^{\text {rd }}$ edition). Baltimore: Johns Hopkins University Press, 2008. 
SOARES, G. "As Bases Ideológicas do Lacerdismo." Revista Civilização Brasileira, vol.1, n4, p.49-70, 1961.

VEIGA, L. "Os partidos brasileiros na perspectiva dos eleitores." Opinião Pública, vol.13, n², p.340-65, 2007.

David Samuels·dsamuels@umn.edu

Tradução do original em inglês de Rachel Meneguello

Recebido e aprovado para publicação em agosto de 2008. 